\title{
VULNERABILIDADE SOCIOAMBIENTAL DO BAIXO CURSO DA BACIA HIDROGRÁFICA DO RIO COCÓ, FORTALEZA-CE
}

\section{Vulnerability Socioenvironmental of Down Progress of Cocó River's Watershed, Fortaleza-CE (Brazil)}

\author{
Maria Elisa Zanella \\ Profa. Dra. do Depto. de Geografia, Universidade Federal do Ceará, \\ Bolsista Produtividade em Pesquisa, CNPq \\ elisazv@terra.com.br
}

João Luís Olímpio Mestrando em Geografia, Bolsista FUNCAP, UFC olimpio.jls@hotmail.com

Maria Clélia Lustosa Costa Profa. Dra. do Depto. de Geografia, UFC clelialustosa@gmail.com

Eustógio Wanderley Correia Dantas Profa. Dra. do Depto. de Geografia, Universidade Federal do Ceará, Bolsista Produtividade em Pesquisa, CNPq edantas@ufc.br

Artigo recebido em 07/01/2013 e aceito para publicação em 02/04/2013

Resumo O presente estudo trata da vulnerabilidade ambiental, social e socioambiental do baixo curso da bacia hidrográfica do rio Cocó, em Fortaleza-CE. A metodologia consistiu na utilização dos Sistemas de Informações Geográficas para elaboração e integração dos mapas de geologia, geomorfologia, pedologia, cobertura vegetal, uso e infraestrutura urbana e dados sociais e econômicos, a fim de se obter a vulnerabilidade natural, ambiental, social e por fim, a socioambiental. Os resultados obtidos indicam que os ambientes de maior vulnerabilidade ambiental coexistem com os de maior vulnerabilidade social, ampliando os problemas socioambientais daqueles espaços. $\mathrm{O}$ mapeamento da vulnerabilidade visa contribuir para $\mathrm{o}$ planejamento urbano-ambiental do baixo curso da bacia e neste sentido os Sistemas de Geoinformação foram fundamentais para a sua espacialização.

Palavras-Chaves: SIG; Vulnerabilidade socioambiental; bacia hidrográfica.

Abstract The following study is about the vulnerability environmental, social and socio environmental of down progress of Coco river's watershed, at Fortaleza-CE. The methodology has been based in the use of Geographic Information Systems to the preparation and integration of geology maps, geomorphology, vegetation, vegetation, urban infrastructure and economic and social information with the view to get the natural vulnerability, environmental, social and finally the socio environmental. The results indicate that the environments of high environmental vulnerability coexist with the high social vulnerability, expanding the socio environmentals problems of those spaces. The vulnerability mapping aims to contribute to the urban-environmental planning of watershed down progress and this sense the Geoinformation System has been primordial to itself spatialization.

Keywords: SIG; Socio environmental vulnerability; watershed. 


\section{INTRODUÇÃO}

Os problemas relacionados às inundações urbanas vêm gerando preocupações e motivando estudos nas diferentes áreas do conhecimento. Contudo, é fundamental o tratamento destas questões dentro de uma abordagem integrada, dado ao grande número de variáveis envolvidas e à complexidade existente.

As diversas formas de produção do espaço geográfico exercem forte pressão sobre o espaço natural, sendo realizadas, na maioria das vezes, sem considerar a vulnerabilidade dos grupos sociais e dos sistemas naturais, por vezes ampliando as condições de risco a que estão expostas parcela da população urbana. Neste sentido, as bacias hidrográficas urbanas são o palco de inúmeros problemas socioambientais, repercutindo negativamente na qualidade de vida das populações que lá residem.

Ressalta-se que a ocupação das planícies de inundações é um exemplo do processo historicamente excludente de constituição dos espaços urbanos brasileiros, onde aquelas foram destinadas às populações socialmente vulneráveis, de modo que é crescente a quantidade de indivíduos atingidos por desastres hidroclimatológicos.

Reconhecidamente, as bacias hidrográficas são unidades espaciais de estudo da Geografia, uma vez que os cursos d'água são um dos principais elementos da paisagem, responsáveis pela esculturação da superfície terrestre (CHRISTOFOLETTI, 1980). $\mathrm{Na}$ Geografia Física, ela é reconhecida como unidade espacial de análise desde o fim dos anos 1960, quando Chorley descreveu a bacia hidrográfica como a unidade geomorfológica fundamental (BOTELHO; SILVA, 2004). Nas últimas décadas, ela foi incorporada por diversos profissionais, estando presente em estudos técnicos e científicos de diferentes ordens.

Enquanto unidade natural, a bacia hidrográfica pode ser conceituada como uma área da superfície terrestre que drena água, sedimentos e materiais dissolvidos em um canal fluvial (COELHO NETO, 2007). Entretanto, a necessidade de uso das águas, planícies, terraços fluviais e demais áreas emersas resultou em diversos impactos, mudanças na paisagem e na dinâmica natural, de modo que o conceito de bacia atual transcende o simples espaço natural. Tal afirma- ção torna-se ainda mais assertiva quando se analisa a situação ambiental das cidades (BOTELHO, 2011), na qual o comportamento hidrodinâmico das águas foi alterado por uma série de intervenções nos canais fluviais, assim como modificações no ciclo hidrológico e na composição física, química e biológica das águas.

Neste sentido, as bacias hidrográficas estão estruturadas como um sistema, no qual a relação entre os diferentes componentes formam uma paisagem singular, marcada por uma dinâmica específica. Enfatiza-se que os componentes não se limitam aos elementos naturais, mas envolvem a sociedade, através dos reflexos de suas ações (processo produtivo, relações imateriais e as condições sociais, econômicas e institucionais) sobre a dinâmica hidrológica e dos demais processos associados.

Portanto, a bacia hidrográfica é uma unidade de investigação de comportamento sistêmico, no qual as variáveis naturais e humanas nela presentes estão sempre em interação. Sua importância como unidade de pesquisa, planejamento e gestão territorial justifica-se pela possibilidade de visualização concreta das inter-relações entre os seus componentes.

Deste modo, considera-se que a bacia hidrográfica corresponde a uma unidade de planejamento ambiental, pois permite conhecer os componentes, processos e interações que nela ocorrem, com intuito de subsidiar um ordenamento territorial pautando sobre princípios da sustentabilidade. Nela é possível analisar como determinada ação humana repercutirá sobre o equilíbrio hidrológico da bacia, refletindo na estabilidade e na qualidade ambiental (BOTELHO; SILVA, 2004).

O planejamento por bacias, principalmente com relação ao uso da água, é respaldado pela Lei Federal $n^{\circ} 9.433$ (BRASIL, 1977), a qual consiste na unidade territorial de implantação da Política Nacional de Recursos Hídricos, instrumento básico de ordenamento territorial, tendo a função de orientar o desenvolvimento, indicar as diretrizes para o crescimento econômico associado à justiça social em condições ecologicamente equilibradas, envolvendo os aspectos naturais e humanos das bacias, além de ser um instrumento potencialmente indutor da conservação e recuperação ambiental (BRAGA, 2009).

As ações relacionadas ao planejamento não devem se restringir apenas aos aspectos naturais, mas 
estar inserida em uma política de planejamento territorial, envolvendo, de forma integrada, os objetivos e as atividades desenvolvidas nos planejamentos setoriais e ambientais (RODRIGUEZ, SILVA; LEAL, 2011).

Ressalta-se que a aplicação das geotecnologias, principalmente por meio dos Sistemas de Informação Geográfica (SIG), tem demonstrado ser eficiente para análises das interações das ações humanas sobre o meio físico e biológico, permitindo obter informações complementares a respeito destas influências mútuas.

Por meio das técnicas de geoprocessamento, tornou-se possível gerar produtos que possam contribuir para uma melhor planificação territorial, especialmente no estudo da vulnerabilidade A superposição das camadas de informação da base cartográfica digital permite a visualização das informações espaciais e relacionamentos, de modo a melhorar a interpretação e compreensão das características ambientais, sociais e das relações que ocorrem em um determinado espaço. Assim, os elementos naturais e sociais podem ser visualizados de forma integrada, estabelecendo-se vulnerabilidades.
Este trabalho visa identificar as áreas de maior vulnerabilidade socioambiental do baixo curso da bacia hidrográfica do rio Cocó, por meio da análise dos elementos naturais, da qualidade de infraestrutura e por meio dos indicadores socioeconômicos. Tais informações são uma importante fonte de dados espaciais para o ordenamento, objetivando contribuir para a gestão do território urbano.

\section{A BACIA HIDROGRÁFICA DO RIO COCÓ}

A bacia hidrográfica do rio Cocó drena a Região Metropolitana de Fortaleza e está situada na porção norte/nordeste do estado do Ceará. O seu baixo curso, área escolhida como recorte espacial para o presente estudo, corresponde à área drenada inserida no município de Fortaleza (Figura 1), portanto é o setor mais urbanizado da bacia. Grosso modo, a apropriação deste espaço é complexa, remetendo a ocupação de populações socialmente menos favorecidas, confrontando-se com o processo atual de expansão urbana, voltada para parcela mais abastada da cidade.

Figura 1 - Mapa de localização do baixo curso do rio Cocó

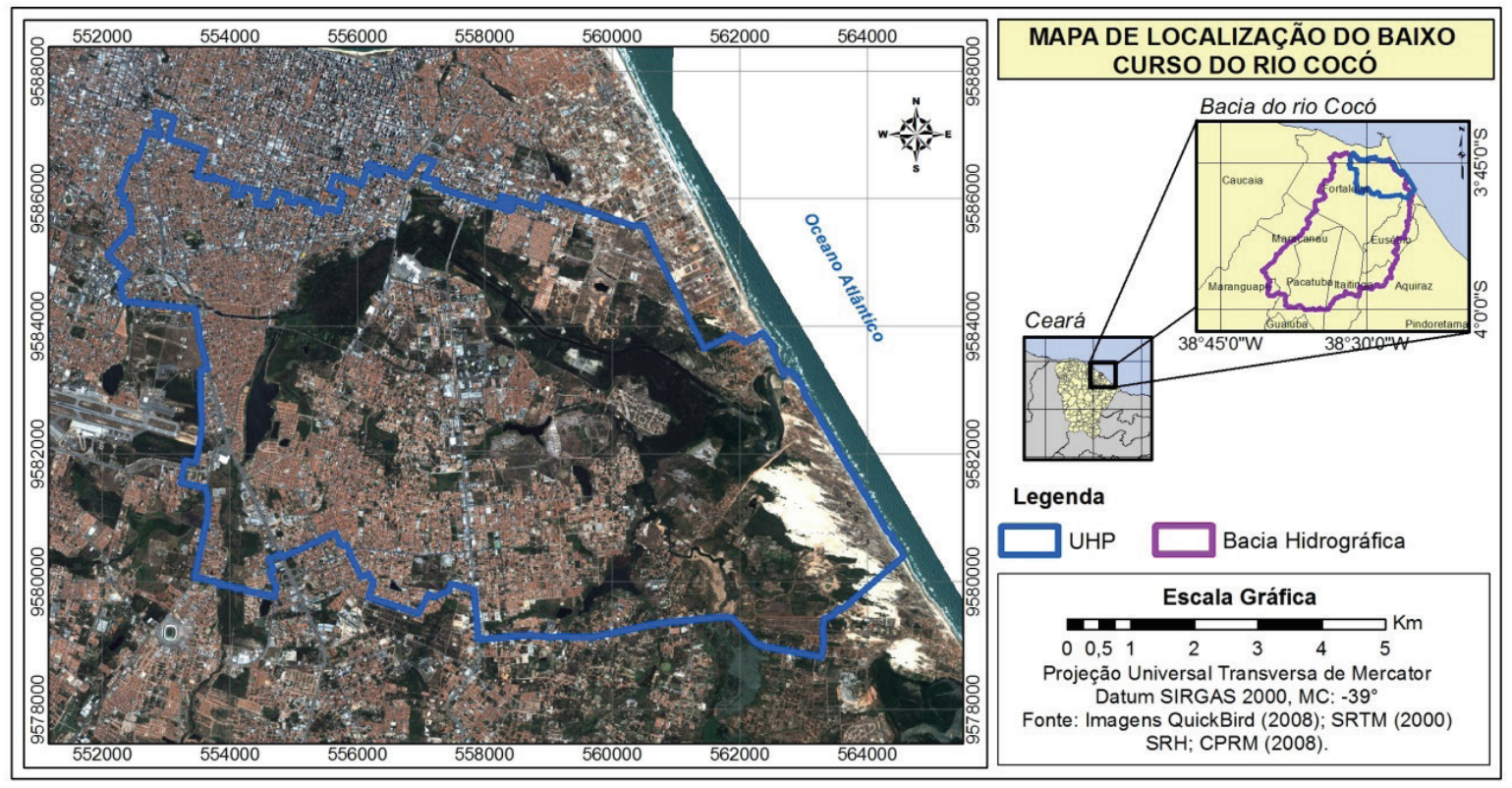

Elaboração dos autores. 
O alto curso bacia está localizado em áreas de maciços cristalinos (vertente úmida da Serra da Aratanha), onde se desenvolvem solos espessos (Argissolos), recobertos pela Mata Úmida. A conservação da vegetação nas áreas mais elevadas da serra se deve à transformação desta em uma unidade de conservação, importante para a manutenção das nascentes das drenagens.

Após descerem as serras, os rios adentram nas áreas aplainadas da Depressão Sertaneja, onde os solos apresentam-se mais rasos, tendo-se como cobertura vegetal dominante a caatinga, atualmente descaracterizada pelas as atividades agropecuárias desenvolvidas. Em seu médio e baixo cursos o rio drena sobre os Tabuleiros Costeiros, onde ocorrem Argissolos e Neossolos Quartzarênicos sustentando a Mata de Tabuleiro, hoje ocupada pela malha urbana de Fortaleza. Finalmente, drena sobre a Planície Litorânea, cujas formas são representadas pelos campos de dunas, terraços marinhos e praias, também ocupadas pelo uso urbano.

Em suas margens, principalmente em seu médio e baixo curso, o rio Cocó desenvolve extensas áreas planas que são submetidas às inundações periódicas. Essas planícies são formadas por aluviões, os quais deram origem aos Neossolos Flúvicos, sustentando uma cobertura vegetal de mata ciliar. $\mathrm{Na}$ desembocadura, influenciada pelas marés, forma-se uma planície fluviomarinha, cuja vegetação existente são os mangues. Grosso modo, essas planícies encontram-se ocupadas por população carentes, que por ocasião de chuvas mais intensas, é submetida às adversidades desse ambiente.

É importante considerar, ainda, que grande parte da área do baixo curso da bacia encontra-se impermeabilizada, não permitindo a infiltração das águas das chuvas, facilitando o aumento do escoamento das águas pluviais e a ocorrência de inundações, principalmente onde a infraestrutura da drenagem pluvial não tem capacidade para escoar a água precipitada.

\section{MATERIAIS E MÉTODOS}

Muitas discussões acerca do conceito de vulnerabilidade têm sido feitas nas últimas décadas, haja vista que o termo está sendo empregado em diferen- tes áreas do conhecimento. Vulnerabilidade natural, ambiental, social e socioambiental são expressões encontradas nas mais diversas literaturas.

Para as geociências o termo vulnerabilidade vem sendo utilizado para expressar a instabilidade dos ambientes. Para Tricart (1977) e Grigio (2003), a vulnerabilidade natural (ou fragilidade ambiental) consiste no maior ou menor estágio de estabilidade/ instabilidade dos elementos físicos e bióticos, frente à intensidade, dinâmica e magnitude dos processos morfogenéticos, pedogenéticos e de fitosucessão.

Enquanto a vulnerabilidade ambiental entende-se pela capacidade de resposta do meio aos efeitos adversos provocados por ações antrópicas, variando conforme suas características naturais e humanas e afetando diretamente a estabilidade do meio, bem como sua qualidade ambiental (SANTOS; CALDEYRO, 2007; TAGLIANI, 2002). Neste sentido, além dos elementos naturais e da dinâmica reinante também são considerados as intervenções antropogênicas e suas reflexões no comportamento dos espaços naturais.

Nas ciências da sociedade, a vulnerabilidade social decorre de fenômenos diversos, com causas e consequências distintas, que afetam de forma diferenciada as pessoas e os grupos sociais. As condições culturais, étnicas, políticas, econômicas, educacionais, sociais e de saúde vão tornar as pessoas e os grupos sociais mais ou menos vulneráveis, ou seja, refletem na capacidade de enfrentar, superar ou minimizar as dificuldades e aproveitar as oportunidades para melhorar sua situação de bem-estar. Nesta condição, conforme Katzman (1999), deve-se considerar também a situação das pessoas quanto à inserção e estabilidade no mercado de trabalho, a debilidade de suas relações sociais e o grau de regularidade de acesso aos serviços públicos ou a outras formas de proteção social.

Kowarick (2002) enfatiza a relação entre desigualdade urbana e vulnerabilidade social, apontando a situação de desproteção em que vastas camadas populacionais estão submetidas, especialmente em relação aos eixos moradia, emprego/desemprego e violência. Nesta mesma perspectiva, Cardoso (2008) destaca as dificuldades enfrentadas por grupos vulneráveis ao acesso aos bens de caráter social e as condições básicas à sobrevivência, como: moradia, solo urbano 
e o conjunto de equipamentos, serviços e amenidades. Para Rodrigues (2006) a vulnerabilidade social também está relacionada à ausência de condições de vida dignas na esfera da produção e reprodução da vida e de representação política, decorrentes de um excesso de exploração e espoliação.

Já a vulnerabilidade socioambiental incorpora a vulnerabilidade ambiental com a vulnerabilidade social. Deschamps (2004) mostra que populações em situação de vulnerabilidade social alta coexistem com espaços naturais susceptíveis aos eventos naturais adversos. Tais áreas geralmente são habitadas por indivíduos e famílias que não possuem recursos de qualquer natureza para responderem adequadamente à ocorrência de um evento natural perigoso. A autora conclui que:

Há uma estreita relação entre a localização espacial dos grupos que apresentam desvantagens sociais e aquelas áreas onde há risco de ocorrer algum evento adverso, ou seja, populações socialmente vulneráveis se localizam em áreas ambientalmente vulneráveis. (DESCHAMPS, 2004, p.140).

Deste modo, a vulnerabilidade socioambiental pode ser definida como um espaço onde coexistem ambientes e populações em situação de risco, expondo aos indivíduos e os grupos sociais às adversidades decorrentes de fenômenos naturais severos (ZANELLA et al, 2009).

\section{ROTEIRO METODOLÓGICO PARA A CONS- TRUÇÃO DO ÍNDICE DE VULNERABILIDADE SOCIOAMBIENTAL}

Para a compressão da vulnerabilidade socioambiental é necessário o entendimento inicial, de forma separada, dos elementos, processos e interações que comandam as dinâmicas socioespaciais e socioambientais. Deste modo, a obtenção da vulnerabilidade socioambiental se deu durante três momentos distintos, a saber: o primeiro consistiu na determinação na vulnerabilidade social, o segundo na análise da vulnerabilidade ambiental e por fim, houve a integração destas duas para a definição da vulnerabilidade socioambiental da bacia. A seguir é apresentado roteiro metodológico para a construção do Índice de Vulnerabilidade Socioambiental.

\section{Índice Sintético de Vulnerabilidade Social - ISVS}

Esta pesquisa utilizou a proposta de Rosa e Costa (2009) para a determinação da vulnerabilidade social do município de Fortaleza, cuja adaptação foi realizada para o baixo curso do rio Cocó. Estas autoras construíram um banco de dados com informações georreferenciados, utilizando como unidade de análise os setores censitários do Censo Demográfico do IBGE (2000). Este índice foi construído a partir da análise e integração dos dados referentes às variáveis: educação, renda e qualidade da habitação (Tabela 1). 
Tabela 1 - Variáveis para construção do Índice Sintético de Vulnerabilidade Social

\begin{tabular}{|c|c|c|}
\hline Educação & Renda & Qualidade da habitação \\
\hline $\begin{array}{l}\text { Mulheres responsáveis analfabetos } \\
\text { Mulheres responsáveis sem instrução ou } \\
\text { com até } 3 \text { anos de estado }\end{array}$ & $\begin{array}{l}\text { Mulheres responsáveis sem rendi- } \\
\text { mento ou com rendimento mensal } \\
\text { de até } 2 \text { salários mínimos }\end{array}$ & $\begin{array}{l}\text { Domicílios particulares permanentes que não } \\
\text { possuem abastecimento de água da rede e de } \\
\text { poço ou nascente na propriedade e canalização } \\
\text { em pelo menos um cômodo }\end{array}$ \\
\hline $\begin{array}{l}\text { Homens alfabetizados responsáveis por } \\
\text { domicílios particulares permanentes } \\
\text { Homens responsáveis por domicílios } \\
\text { particulares permanentes sem instrução } \\
\text { ou com até } 3 \text { anos de estudo }\end{array}$ & $\begin{array}{l}\text { Homens responsáveis por domi- } \\
\text { cílios particulares permanentes } \\
\text { sem rendimento e com rendimento } \\
\text { nominal mensal de até } 2 \text { salário } \\
\text { mínimos }\end{array}$ & $\begin{array}{l}\text { Domicílios particulares que não possuem ba- } \\
\text { nheiro ou sanitário ligado a rede de esgoto ou } \\
\text { com fossa séptica } \\
\text { Domicílios particulares permanentes que não } \\
\text { possuem lixo coletado por serviços de limpeza } \\
\text { ou caçamba e sem outro destino do lixo }\end{array}$ \\
\hline
\end{tabular}

Fonte: Rosa e Costa (2009).

Em seguida, foram calculados os percentuais de cada indicador, inserindo-os em uma equação que os transforma em um índice que varia de 0 a 1 , onde os valores mais próximo de 1 apresentam as condições sociais e econômicas mais agravantes, enquanto as mais próximas de 0 correspondem a situação inversa.

Índice $=\frac{\text { valor observado da variável }(\mathrm{em} \%) \text { - pior valor da variável no universo de análise (em \%) }}{\text { melhor valor da variável no universo de análise (em \%) - pior valor da variável no universo de análise (em \%) }}$

Posteriormente, foram realizadas médias ponderadas para cada variável em análise. Para as variáveis educação e renda considerou se que quando o chefe de família era mulher recebia peso 2 e quando homem peso 1. Para qualidade da habitação, acesso a água recebia peso 3 , o esgotamento sanitário 2 e a coleta de lixo 1. Por fim, ocorreu a integração estes indicadores obtendo-se o Índice Sintético de Vulnerabilidade Social. Este índice possibilita a análise das desigualdades socioespaciais presentes na área em estudo, a partir da amplitude das variáveis selecionadas entre os setores censitários do município de Fortaleza.

\section{ÍNDICE DE VULNERABILIDADE AMBIEN- TAL - IVA}

Para a construção do Índice de Vulnerabilidade Ambiental (IVA) empregou-se os princípios da análise ecodinâmica, fundamentada sobre os conceitos de estabilidade e instabilidade ambiental, estabelecidas em função da predominância dos processos morfogenéticos/pedogenéticos (TRICART, 1977) e o consequente risco de desastres naturais. Por meio desta relação são constituídas as unidades ecodinâmica definidas como um espaço territorial natural, funcionando como um sistema e mantendo relações entre os diversos componentes em fluxos de energia e matéria que as distinguem no espaço. Neste sentido, a partir da instabilidade se identificou aquelas áreas mais vulneráveis aos riscos de deslizamentos, soterramentos, erosão marinha e inundações.

A metodologia utilizada no IVA consistiu na integração de valores indicativos da instabilidade de cada atributo dos meios físico, biótico e da qualidade da infraestrutura do espaço urbano. Estes valores foram adaptados da metodologia empregada por Costa et al (2006) e Grigio (2003), em função da relação de predomínio entre os processos morfo/pedogenéticos. Assim, da mesma forma que o ISVS, cada atributo 
recebeu um valor que varia de 0 a 1 , sendo que os mais próximos de 1 são mais vulneráveis e os mais próximo de 0 são menos (Tabela 2).

Foram gerados os mapas de geologia, geomorfologia, pedologia e cobertura vegetal, sendo em seguida atribuídos valores indicativos da intensidade da vulnerabilidade. O cruzamento destas variáveis resultou no mapa de vulnerabilidade natural. Em seguida, houve o cruzado deste com o mapa da qualidade da infraestrutura urbana, obtendo-se o mapa de vulnerabilidade ambiental.

\section{ÍNDICE DE VULNERABILIDADE SOCIOAM- BIENTAL - IVSO}

Após a construção dos índices de vulnerabilidade social e ambiental, bem como a espacialização dos mesmos, procedeu-se o cruzamento das mesmas, resultando em um mapa de vulnerabilidade socioambiental.

Tabela 2 - Índice de Vulnerabilidade Ambiental

\begin{tabular}{|c|c|}
\hline Atributos Ambientais & Índice de Vulnerabilidade Ambiental \\
\hline \multicolumn{2}{|c|}{ Geologia } \\
\hline Sedimentos Lacustres & 1 \\
\hline Sedimentos Fluviomarinhos & 1 \\
\hline Sedimentos Aluviais & 1 \\
\hline Depósito Eólico Litorâneo & 1 \\
\hline Depósito Eólico Litorâneo (Dunas) & 1 \\
\hline Formação Barreiras & 0 \\
\hline \multicolumn{2}{|c|}{ Geomorfologia } \\
\hline Tabuleiros Pré-Litorâneos & 0 \\
\hline Dunas Fixas & 0,5 \\
\hline Área de Inundação Sazonal & 1 \\
\hline Planície Fluviomarinha com Mangue & 1 \\
\hline Planície Fluvial & 1 \\
\hline Planície Lacustre & 1 \\
\hline Dunas Móveis & 1 \\
\hline Terraços Marinhos & 1 \\
\hline Faixa de Praia & 1 \\
\hline \multicolumn{2}{|c|}{ Pedologia } \\
\hline Gleissolos & 1 \\
\hline Neossolos Flúvicos & 0,75 \\
\hline Neossolos Quartzarênicos & 0,75 \\
\hline Planossolos & 0,75 \\
\hline Neossolos Regolíticos & 0,5 \\
\hline Argissolos Vermelho-Amarelos & 0,25 \\
\hline \multicolumn{2}{|c|}{ Cobertura Vegetal } \\
\hline Sem Cobertura Vegetal & 1 \\
\hline Sem Cobertura Vegetal (Dunas Móveis) & 1 \\
\hline Vegetação de Mangue & 0,75 \\
\hline Vegetação Ribeirinha/Lacustre & 0,75 \\
\hline Vegetação Subperenifólia de Tabuleiro & 0 \\
\hline \multicolumn{2}{|l|}{ Qualidade da infraestrutura urbana } \\
\hline Áreas com Infraestrutura Precária & 1 \\
\hline Áreas com Infraestrutura Mediana & 0,5 \\
\hline Áreas com Infraestrutura Consolidada & 0 \\
\hline
\end{tabular}

Fonte: adaptado de Costa et al, 2006; Zanella, Dantas e Olímpio, 2011. 
As feições espaciais contendo as informações sobre as vulnerabilidades ambiental e social foram superpostas, para em seguida serem cruzadas, em forma de matrizes, resultando em unidades espaciais que apresentam o mosaico das situações possíveis (Quadro 1).

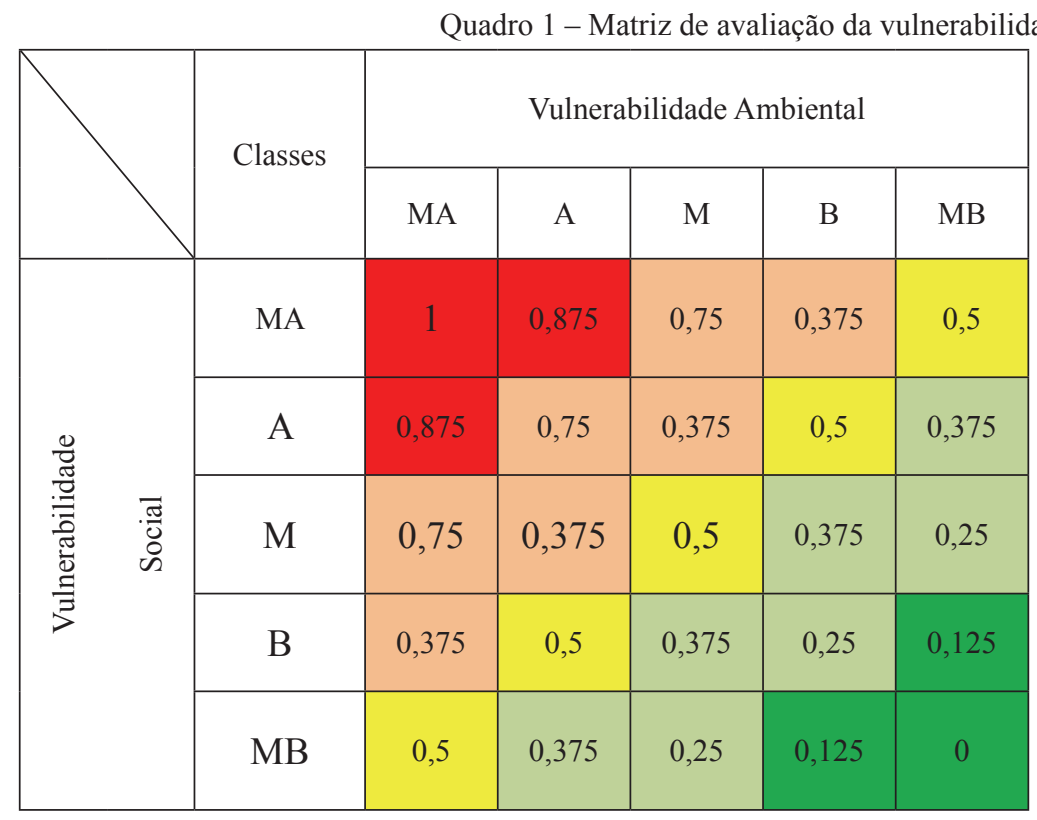

\begin{tabular}{|c|c|}
\hline \multicolumn{2}{|c|}{ Legenda } \\
\hline & MA $=$ Muito Alta \\
\hline & $\mathrm{A}=\mathrm{Alta}$ \\
\hline $\mathrm{M}=$ Mediana \\
\hline $\mathrm{B}=$ Baixa \\
\hline $\mathrm{MB}=$ Muito Baixa \\
\hline
\end{tabular}

Org. dos autores.

PROCEDIMENTOS TÉCNICO-OPERACIONAIS

Para a produção do material cartográfico empregou-se o software ArcGis 9.3. Os mapeamentos foram realizados sobre imagens QuickBird, datadas de 2008, com resolução espacial de 2,44 a 2,88 metros. Também foram utilizadas diversas bases cartográficas disponibilizadas pela Prefeitura Municipal de Fortaleza, bem como os setores censitários para o ano de 2000, fornecidos pelo IBGE.

Para a delimitação espacial da bacia hidrográfica foram aplicadas um conjunto de rotinas operacionais sobre as imagens interferomértricas SRTM (Shuttle Radar Topography Mission), com resolução espacial de 90 metros. Entretanto, devido à incompatibilidade do padrão espacial dos elementos do quadro natural e socioeconômico, optou-se por definir a área de estudo em Unidades Hidrográficas de Planejamento (UHP). Assim, a área de estudo foi delimitada em função do limite geográfico na bacia hidrografia, mas realizando-se ajustes no mesmo para adequá-los aos polígonos dos setores censitários. Foram considerados integrantes da UHP todos os setores que apresentam pelo menos $50 \%$ de sua área no interior do polígono do baixo curso da bacia hidrográfica. Como critério para a delimitação do baixo curso considerou-se até aonde se faz sentir as influências das marés para montante.

Posteriormente, realizou-se o mapeamento dos atributos ambientais, a partir das técnicas de interpretação de imagens, possibilitando uma melhor definição espacial dos elementos em análise. Também, foram realizados diversos trabalhos de campo, visando à checagem dos mapeamentos realizados, além de verificar o grau de vulnerabilidades das diversas porções do espaço estudado.

\section{VULNERABILIDADE SOCIAL: O CONTEXTO SOCIOECONÔMICO E A EX- POSIÇÃO AOS RISCOS}

Por meio dos dados dos setores censitários do IBGE, considerando a educação, a renda e a qualidade da habitação (ROSA; COSTA, 2009) foi estabelecida a vulnerabilidade social (Figura 2), sendo as seguintes:

Vulnerabilidade baixa e muito baixa: correspondem às áreas mais consolidadas e valorizadas do baixo curso da bacia, predominando populações com 
baixas taxas de analfabetismo, ótimas condições de renda e moradia. São indivíduos mais propensos a superar e suportar as adversidades promovidas pelas diversas formas de risco.

Vulnerabilidade média: localizam-se em áreas em que predominam populações de renda média e baixa, mas habitando áreas melhor providas de ser- viços urbanos básicos. São parcialmente sujeitos as adversidades, podendo superá-las deste que a intensidade dos eventos naturais não supere a capacidade de resistência da população.

Figura 2 - Mapa de Vulnerabilidade Social do Baixo Curso da Bacia do rio Cocó.

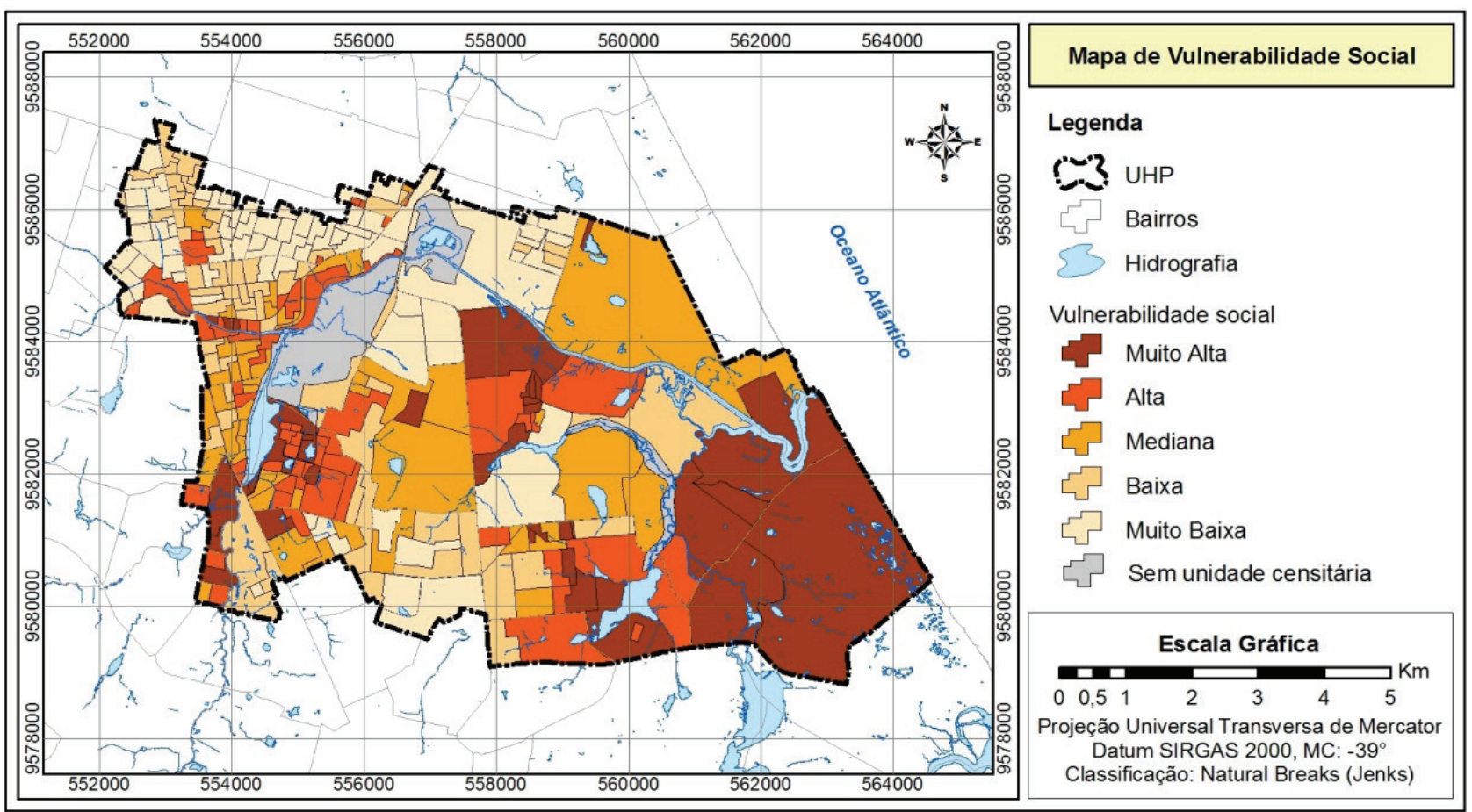

Elaboração dos autores.

Vulnerabilidade alta e muito alta: localizam-se onde os setores censitários se encontram em áreas inundáveis ou com campos de dunas, cujas condições de moradia são precárias, a população apresenta baixo nível de escolaridade e com renda próxima a um salário mínimo. Assim, a população residente não tem condições para enfrentar os eventos naturais adversos.

\section{VULNERABILIDADE AMBIENTAL: A DINÂ- MICA DOS PROCESSOS NATURAIS}

Com apresentado anteriormente, inicialmente definiu-se a vulnerabilidade natural, para então determinar a vulnerabilidade ambiental. A figura 3 apresenta o mapa de vulnerabilidade natural da área em estudo e no quadro 2 são indicados os componentes naturais constituintes e a dinâmica de cada classe de vulnerabilidade. 


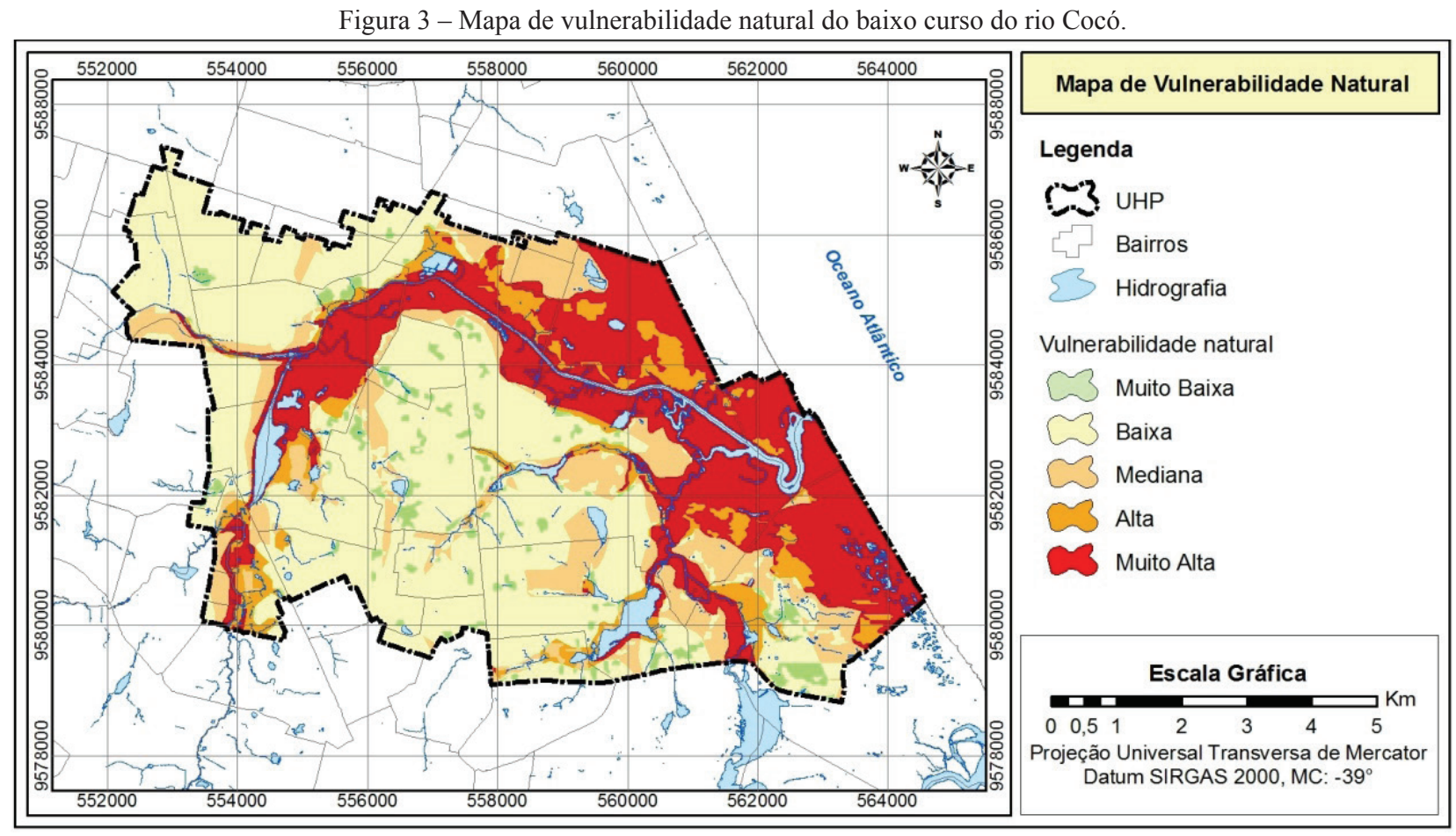

Elaboração dos autores.

O mapa de vulnerabilidade ambiental representa uma importante ferramenta para a tomada de decisão, notavelmente para os gestores públicos, ao indicar espacialmente a dinâmica do meio natural $\mathrm{e}$, consequentemente, indicar as potencialidades e as limitações, bem como os riscos das ocupações impróprias, em cada porção do espaço (OLÍMPIO; ZANELLA, 2012) (Figura 4).
A partir do cruzamento dos referidos atributos obteve-se o mapa de vulnerabilidade ambiental, compartimentado em cinco classes: muito baixa, baixa, média, alta, muito alta, descritas a seguir. 
Vulnerabilidade Socioambiental do Baixo Curso da Bacia Hidrográfica do Rio Cocó, Fortaleza-CE Maria Elisa Zanella, João Luís Olímpio, Maria Clélia Lustosa Costa, Eustógio, Wanderley Correia Dantas

\begin{tabular}{|c|c|c|c|c|c|}
\hline $\begin{array}{c}\text { Vulnerabilidade } \\
\text { Natural }\end{array}$ & $\begin{array}{c}\text { Geologia / Geomor- } \\
\text { fologia }\end{array}$ & $\begin{array}{c}\text { Clima / } \\
\text { Recursos } \\
\text { Hídricos } \\
\end{array}$ & Solos & Cobertura Vegetal & Ecodinâmica \\
\hline Muito Baixa & $\begin{array}{l}\text { Tabuleiros } \\
\text { Pré-Litorâneos } \\
\text { da Formação } \\
\text { Barreiras }\end{array}$ & $\begin{array}{l}\text { Clima } \\
\text { tropical } \\
\text { sub-úmido; } \\
\text { Aquífero } \\
\text { Barreiras. }\end{array}$ & Argissolos & $\begin{array}{l}\text { Mata de Tabulei- } \\
\text { ros em estágio de } \\
\text { avançado e médio } \\
\text { de regeneração e } \\
\text { Vegetação Antrópi- } \\
\text { ca adensada }\end{array}$ & $\begin{array}{l}\text { Áreas naturalmente está- } \\
\text { veis, onde predominam os } \\
\text { processos pedogenéticos. } \\
\text { Não há risco de inunda- } \\
\text { ções }\end{array}$ \\
\hline \multirow[b]{2}{*}{ Baixa } & \multirow{2}{*}{$\begin{array}{l}\text { Tabuleiros } \\
\text { Pré-Litorâneos } \\
\text { da Formação } \\
\text { Barreiras }\end{array}$} & \multirow{2}{*}{$\begin{array}{l}\text { Clima } \\
\text { tropical } \\
\text { sub-úmido; } \\
\text { Aquífero } \\
\text { Barreiras.. }\end{array}$} & Argissolos & $\begin{array}{l}\text { Vegetação Antrópi- } \\
\text { ca pouco adensada } \\
\text { ou Mata de Tabulei- } \\
\text { ro em estado inicial } \\
\text { de regeneração }\end{array}$ & \multirow{2}{*}{$\begin{array}{l}\text { Áreas naturalmente está- } \\
\text { veis, mas que já apresen- } \\
\text { tam morfodinâmica mais } \\
\text { acentuada. Não há risco de } \\
\text { inundações }\end{array}$} \\
\hline & & & $\begin{array}{l}\text { Neossolo Quart- } \\
\text { zarênico e Neos- } \\
\text { solo Flúvico }\end{array}$ & $\begin{array}{l}\text { Mata de Tabulei- } \\
\text { ros em estágio de } \\
\text { avançado e médio } \\
\text { de regeneração e } \\
\text { Vegetação Antrópi- } \\
\text { ca adensada }\end{array}$ & \\
\hline Média & $\begin{array}{l}\text { Tabuleiros } \\
\text { Pré-Litorâneos } \\
\text { da Formação } \\
\text { Barreiras }\end{array}$ & $\begin{array}{l}\text { Clima } \\
\text { tropical } \\
\text { sub-úmido; } \\
\text { Aquífero } \\
\text { Barreiras. }\end{array}$ & $\begin{array}{l}\text { Neossolo Quart- } \\
\text { zarênico e Neos- } \\
\text { solo Flúvico }\end{array}$ & $\begin{array}{l}\text { Vegetação Antrópi- } \\
\text { ca pouco adensada } \\
\text { ou Mata de Tabulei- } \\
\text { ro em estado inicial } \\
\text { de regeneração }\end{array}$ & $\begin{array}{l}\text { Mordinâmica mediana, } \\
\text { mas com tendência a vul- } \\
\text { nerabilidade alta. Risco de } \\
\text { inundação excepcional }\end{array}$ \\
\hline \multirow{2}{*}{$\begin{array}{l}\text { Alta e } \\
\text { Muito Alta }\end{array}$} & $\begin{array}{l}\text { Dunas Fixas, } \\
\text { Móveis, Terraços } \\
\text { Marinhos e Faixa } \\
\text { de Praia (de- } \\
\text { pósitos Eólicos } \\
\text { Litorâneos) }\end{array}$ & $\begin{array}{l}\text { Clima } \\
\text { tropical } \\
\text { sub-úmido; } \\
\text { Aquífero } \\
\text { Dunas }\end{array}$ & $\begin{array}{l}\text { Neossolo Quart- } \\
\text { zarênico }\end{array}$ & $\begin{array}{l}\text { Vegetação Subpere- } \\
\text { nifólia de Dunas e } \\
\text { Vegetação Pioneira } \\
\text { Psamófila }\end{array}$ & \multirow{2}{*}{$\begin{array}{l}\text { Morfodinâmica alta. } \\
\text { Predomínio dos processos } \\
\text { erosivos. Risco de erosão } \\
\text { marinha, soterramentos, } \\
\text { deslizamentos e inunda- } \\
\text { ções sazonais }\end{array}$} \\
\hline & $\begin{array}{l}\text { Planícies fluvial, } \\
\text { lacustre e Fluvio- } \\
\text { marinha (depósito } \\
\text { Aluvionares) }\end{array}$ & $\begin{array}{l}\text { Clima } \\
\text { tropical } \\
\text { sub-úmido; } \\
\text { Aquífero } \\
\text { Aluvião }\end{array}$ & Gleissolo & $\begin{array}{l}\text { Vegetação Palus- } \\
\text { tre Marítima de } \\
\text { Mangue }\end{array}$ & \\
\hline
\end{tabular}

Elaboração dos autores.

Vulnerabilidade muito baixa - corresponde às áreas dos setores oeste e sul do baixo curso, formadas por espaços com vulnerabilidade natural baixa e muito baixa associadas às áreas melhor providas de serviços urbanos básicos. Portanto, são os ambientes de me- lhor qualidade ambiental e menos expostas aos riscos ambientais, sendo as mais promissoras a intervenção antropogênica, deste que ambientalmente planejadas. 
Figura 4 - Mapa de vulnerabilidade ambiental do baixo curso da bacia do rio Cocó.

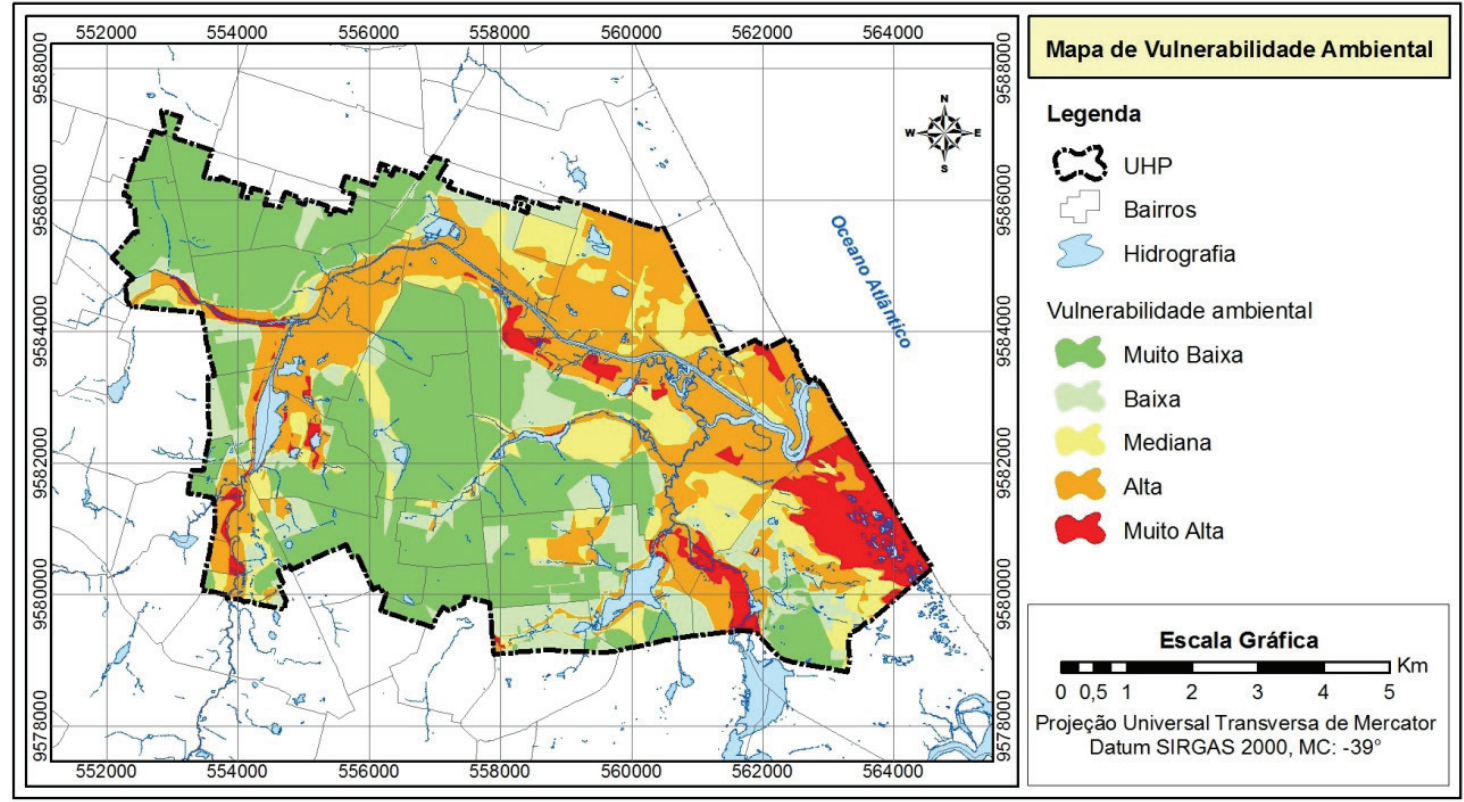

Elaboração dos autores.

Vulnerabilidade baixa - é formada por ambientes de vulnerabilidade natural baixa ou mediana associada às áreas com infraestrutura mediana ou precária. Apesar de apresentarem vulnerabilidade baixa está unidade necessita de adoção de medidas de recuperação, controle e monitoramento ambiental, além da reurbanização das áreas com infraestrutura mediana e precária.

Vulnerabilidade média - são áreas dispostas em manchas por toda a bacia, mas com a maior frequência na planície litorânea. São representadas por mosaicos formados por diversas combinações entre os elementos da paisagem. As intervenções devem considerar o arranjo dos elementos ambientais em nível local, evitando problemas socioambientais futuros.

Vulnerabilidade alta - representam áreas com vulnerabilidade alta e muito alta, como as planícies fluviomarinhas e os campos de dunas, ocupadas por espaços urbanas com infraestruturas medianas, precárias ou vegetadas. Recomenda-se que a expansão urbana sobre estes ambientes seja evitada, pois são propícios a ocorrência de desastres naturais.

Vulnerabilidade muito alta - correspondem aos setores com vulnerabilidade natural muito alta com infraestruturas urbanas precárias, de modo que a dinâmica natural expõe a população aos riscos naturais. São representados pelas planícies litorânea e fluviomarinha degradadas pela ocupação irregular. Observa-se que mesmo em estado natural esta unidade apresentaria vulnerabilidade muito alta, contudo devido aos processos de degradação, este fator é ampliado, colocando em situação de risco a população usuária deste ambiente.

\section{VULNERABILIDADE SOCIOAMBIENTAL: DINÂMICA NATURAL X DINÂMICA SOCIAL}

O mapa de vulnerabilidade socioambiental representa um importante recurso para o processo de tomada de decisão ao indicar espacialmente as condições socioeconômicas da população associando-as a dinâmica dos sistemas naturais, permitindo determinar quais as áreas são mais propícias à ocorrência de desastres naturais, principalmente aos relacionados aos eventos hidroclimatológicos, cujas categorias estão analisadas abaixo (Figura 5). 
Figura 5. Mapa de vulnerabilidade socioambiental do baixo curso da bacia do rio Cocó.

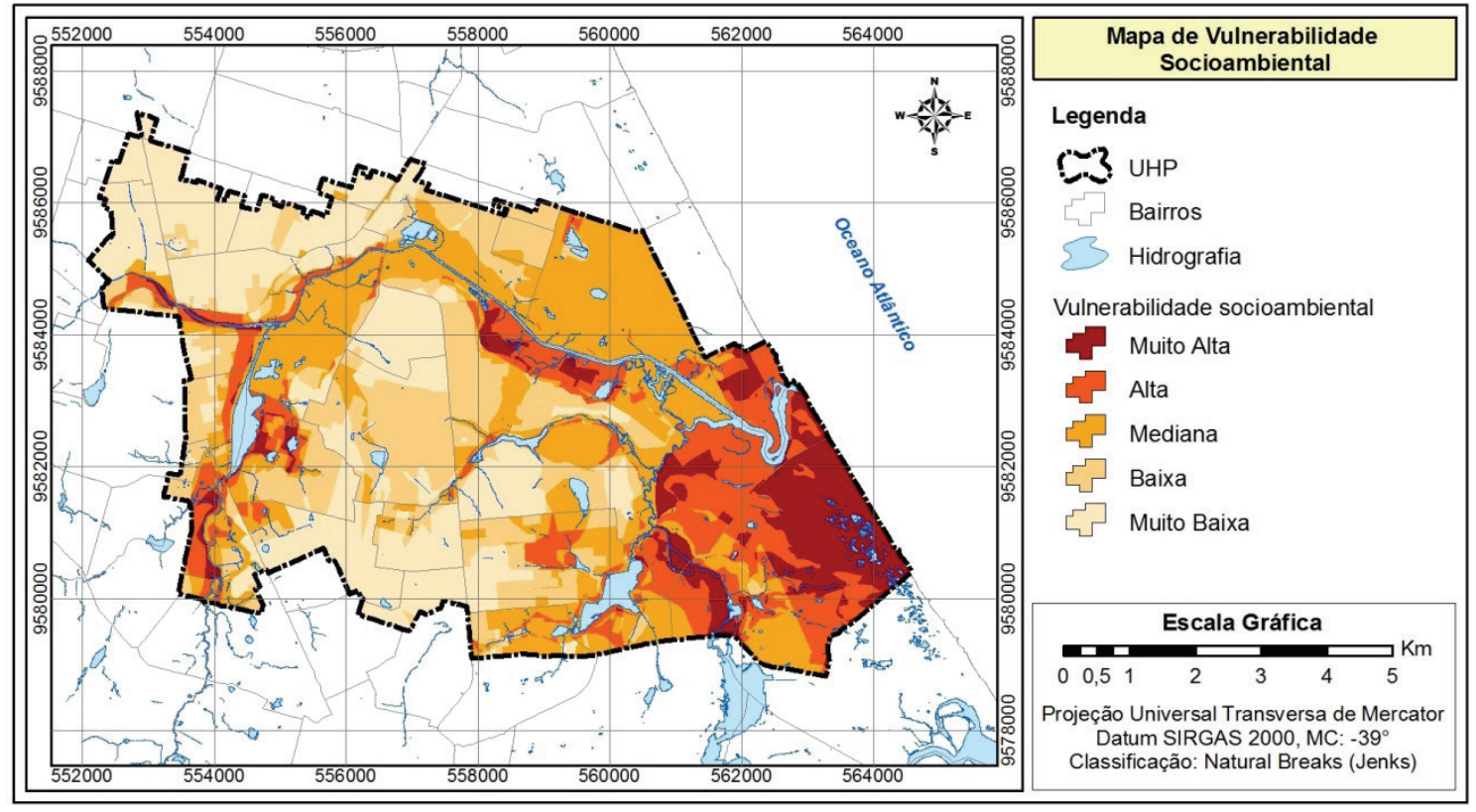

Elaboração dos autores.

Vulnerabilidade muito baixa: consiste nos ambientes mais estáveis do ponto de vista morfodinâmico, associado a populações com melhores condições sociais, abrangendo as áreas mais consolidadas do ponto vista dos serviços urbanos. Nesta unidade devem-se priorizar as atividades de conservação e dos processos de urbanização tendo em vista que são ambientes de relevante interesse para a qualidade ambiental de Fortaleza.

Vulnerabilidade baixa: somando-se as áreas de vulnerabilidade muito baixa, correspondem à maior porção do baixo curso da bacia. São áreas cuja morfodinâmica é bastante estável, a infraestrutura urbana é predominantemente consolidada e a população apresenta boas condições sociais e econômicas.

Vulnerabilidade média: ocupa, predominantemente, áreas com vulnerabilidade ambiental e condições socioeconômicas medianas, mas podendo ter outros combinações, variando conforme as relações entre os elementos naturais e humanos em escala local. Neste sentido, as unidades de baixa e média vulnerabilidade são as melhores áreas para a ocupação, deste que respeitados os preceitos das legislações ambientais e urbanísticas, bem como a adoção de práticas conservacionistas.

Vulnerabilidade alta e muito alta: ocupam áreas de alta e muito alta vulnerabilidade ambiental, associadas às populações mais carentes do ponto de vista socioeconômico. As planícies fluviomarinhas e os campos de dunas degradados constituem os locais onde convivem populações classificadas como de vulnerabilidade social alta e muito alta. Tais áreas são as mais atingidas quando da ocorrência de eventos hidroclimáticos extremos.

\section{CONSIDERAÇÕES FINAIS}

Constatou-se que as vulnerabilidades natural e ambiental predominantes no baixo curso da bacia hidrográfica do rio Cocó são classificadas como baixa e muito baixa, correspondendo aos setores de tabuleiros urbanizados. A classe alta e muito alta representam ambientes que a composição dos elementos ambientais revelou elevada dinâmica ambiental, favorecendo os processos morfogenéticos. A classe de vulnerabilidade ambiental muito alta é constituída por ambientes de vulnerabilidade natural muito alta com infraestrutura precária, ocupadas por populações socialmente vulneráveis e susceptíveis aos eventos naturais severos. Encontrapartida, a classe muito baixa corresponde aos tabuleiros vegetados ou aqueles com infraestrutura urbana consolidada. 
Com relação à vulnerabilidade social, conclui-se que a área de estudo é constituída por espaços com vulnerabilidades elevadas e reduzidas convivendo lado a lado. Verificou-se que a bacia possui extensos setores de alta e muito alta vulnerabilidade, principalmente aqueles localizados em planícies de inundações dos rios e lagoas, campos de dunas habitados, cujas condições de educação, renda e moradia são precárias.

Com relação a vulnerabilidade socioambiental, conclui-se que parte das áreas de alta vulnerabilidade social coexiste com as de maior vulnerabilidade ambiental. A população que lá se instala, pelas suas condições sociais, não tem meios para enfrentar as adversidades daqueles ambientes, ampliando ainda mais os problemas socioambientais.

Nestes termos, considera-se que as políticas e ações de gestão do espaço urbano, devem sistematizar e integrar as informações ambientais, sociais e econômicas, visando medidas coordenadas que melhorem as condições de bem-estar da população, bem como a manutenção e a recuperação dos espaços naturais. Assim, espera-se que as informações produzidas possam dar sua contribuição ao planejamento territorial do baixo curso da bacia, subsidiando o processo de tomada de decisões.

\section{REFERÊNCIAS}

BRAGA, R. Instrumentos para a gestão ambiental e recursos hídricos. Recife: Ed. Universitária UFPE, 2009.

BRASIL. Lei n 9.433, de 08 de janeiro de 1997. Institui a Politica Nacional de Recursos Hídricos e cria o Sistema Nacional de Recursos Hídricos. Brasília, DF, 8 de jan. de 1997.

BOTELHO, R. G. M. Bacias Hidrográficas Urbanas. In: GUERRA, A. J. T. (Org.). Geomorfologia Urbana. Rio de Janeiro, Bertrand Brasil, 2011.

BOTELHO, R. G. M; DA SILVA, A. S. Bacia hidrográfica e Qualidade Ambiental. In: VITTE, A. C; GUERRA, A. J. T. (Org.). Reflexões sobre a Geografia Física no Brasil. Rio de Janeiro: Bertrand Brasil, 2004.
CARDOSO, A. L. Desigualdades urbanas e politicas habitacionais socioeconomicas. Rio de Janeiro: UFRJ. Disponível em: <www.observatoriodasmetropoles. ufrj.br/download/adauto_desig_urb_polhab.pdf $>$. Acessado em: 20 out. 2011.

CHRISTOFOLETTI, A. Geomorfologia. 2 ed. São Paulo: Edgard Blucher, 1980.

COELHO NETO, A. L. Hidrologia de Encosta na Interface com a Geomorfologia. In: GUERRA, A. J. T; CUNHA, S. B. (Org.). Geomorfologia: uma atualização de bases e conceitos. Rio de Janeiro: Bertrand Brasil, 2007. cap. 3

COSTA, F. H. S; PETTA, R. A; LIMA, R. F. S; MEDEIROS, C. N. Determinação da vulnerabilidade ambiental na bacia potiguar, região de Macau (RN), utilizando Sistemas de Informações Geográficas. Revista Brasileira de Cartografia. Rio de Janeiro, n. 58, v. 02, p.119-129, 2006.

DESCHAMPS, M. V. Vulnerabilidade Socioambiental na Região Metropolitana de Curitiba. Curitiba: UFPR, 2004. 155f. Tese de Doutorado - Programa de Pós-Graduação em Meio Ambiente e Desenvolvimento, Universidade Federal do Paraná, Curitiba, 2004.

GRIGIO. A. M. Aplicação de Sensoriamento Remoto e Sistemas de Informação Geográfica na Determinação da Vulnerabilidade Natural e Ambiental do Municipio de Guamaré / $R N$ : simulação de risco das atividades da indústria petrolífera. Natal: UFRN, 2003. 222f. Dissertação de Mestrado, Geodinâmica e Geofísica, Universidade Federal do Rio Grande do Norte, Natal, 2003.

KATZMAN. R. (Coord.). Activos y estructuras de oportunidades: estudios sobre las raíces de la vulnerabilidad social em Uruguay, Montevideo, CEPAL Proyecto Apoyo a la Implementación del, Programa de Acción de la Cumbre Mundial sobre Desarrollo Social, 1997.

KOWARICK, L. Viver em risco: sobre a vulnerabilidade no Brasil urbano. Novos Estudos, Cebrap, n. 63, p. 9-30, 2002. 
OLÍMPIO, J. L. S; ZANELLA, M. E. Emprego das geotecnologias da geoinformação na determinação das vulnerabilidades natural e ambiental do município de Fortaleza / CE. Revista Brasileira de Cartografia, n.64, v.1, p. 01-14, 2011.

RODRIGUES, A. M. Manejo Integrado, risco e vulnerabilidade social: evitar tragédias, corrigir problemas? In: PINHEIRO, D. R. C. (Org.). Desenvolvimento Sustentável: desafios e discursões. Fortaleza: ABC Editora, 2006. p. 9-30.

RODRIGUEZ, J. M. M; SILVA, E. V; LEAL, A. C. Planejamento ambiental em bacias hidrográficas. In: SILVA, E. V. RODRIGUEZ, J. M. M; MEIRELES, A. J. A. (Orgs.). Planejamento ambiental e bacias hidrográficas. Fortaleza: Edições UFC, 2011.

ROSA, S; COSTA, M.C.L. Banco de dados de vulnerabilidade socio ambiental da RMF. In: COSTA, M. C. L; DANTAS, E. W. C. (Orgs.). Vulnerabilidade Socioambiental na Região Metropolitana de Fortaleza. Fortaleza: Edições UFC, 2009.

SANTOS, R. F; CALDEYRO, V. S. Paisagens, Condicionantes e Mudanças. In: SANTOS, R. F. (Org.). Vulnerabilidade Ambiental: desastres ambientais ou fenômenos induzidos?. Brasília: MMA, 2007.
TAGLIANI, C. R. A. A mineração na porção média da Planície Costeira do Rio Grande do Sul: estratégia para a gestão sob um enfoque de Gerenciamento Costeiro Integrado. UFRS, 2002. 252f. Tese de doutorado - Programa de Pós-Graduação em Geociências, Universidade Federal do Rio Grande do Sul, 2002.

TRICART. J. Ecodinâmica. Rio de Janeiro: IBGE, 1977.

ZANELLA, M. E; COSTA, M. C. D; PANIZZA A. C; ROSA, M. V. Vulnerabilidade Socioambiental de Fortaleza. In: DANTAS, E. W. C; COSTA, M. C. L. (Org.). Vulnerabilidade Socioambiental na Região Metropolitana de Fortaleza. Fortaleza: edições UFC, 2009.

ZANELLA, M. E; DANTAS, E. W. C; OLIMPIO, J.L.S. A Vulnerabilidade Ambiental do Município de Fortaleza. Boletim Goiano de Geografia. Goiânia, v. 31, n. 2, p. 13-27, 2011. 